\title{
Neurological Manifestations in COVID-19 Patients: Bangladesh Perspective
}

\author{
Quazi Deen Mohammad', Mohammad Enayet Hussain² \\ ${ }^{1}$ Director and Professor of Neurology, National Institute of Neurosciences \& Hospital, Dhaka, Bangladesh; \\ ${ }^{2}$ Associate Professor, Department of Neurology, National Institute of Neurosciences \& Hospital, Dhaka, \\ Bangladesh
}

Involvement of the nervous system after viral infection is common. SARS CoV-2, which emerged first in China at the end of year 2019, is not primarily neurotropic virus. The primary target is the respiratory epithelium although it has exhibited neurotropic properties with various neurological manifestations. The target receptor for attachment to cell and subsequent internalization is through the angiotensin converting enzyme-2 receptor (ACE 2) located abundantly in lung alveolar epithelial cells, enterocytes of the small intestine, arterial and venous endothelial cells and arterial smooth muscle cells in all organs ${ }^{1}$. After entry into the cell the virus RNA is released in the cytoplasm which is subsequently translated and replicated. After formation of envelope protein and incorporation of RNA into the virus it is released in the circulation ${ }^{2}$.

Two mechanisms have been implicated for neurological damage among Covid-19 patients. Firstly, severe pneumonia causes systemic hypoxia resulting in neuronal swelling and brain edema which ultimately results in neurological damage. The contributory factors are peripheral vasodilatation, hypercarbia, hypoxia and anaerobic metabolism with accumulation of toxic compounds $^{3}$. If the hypoxia continues unabated, cerebral edema and the cerebral circulation disorder may worsen sharply. With intracranial hypertension, the brain function gradually deteriorates resulting in drowsiness, bulbar conjunctival edema, and even coma ${ }^{4}$. In addition, for patients at particular risk of developing cerebrovascular disease, hypoxia may also induce the occurrence of acute cerebrovascular disease such as acute ischemic stroke ${ }^{5}$. Secondly, cytokine storms with increased levels of inflammatory cytokines and activation of $\mathrm{T}$ lymphocytes, macrophages, and endothelial cells lead to immune-mediated injury. Hypercytokinemia causes vascular leakage, activation of complement and coagulation cascade, disseminated intravascular coagulation and end organ damage ${ }^{6-7}$.

The neurological symptoms associated with COVID-19 include headache, dizziness, depression, anosmia, encephalitis, stroke, epileptic seizures, and Guillain-Barre syndrome along with many others ${ }^{8}$.

National Institute of Neuroscience and Hospital, Dhaka is the only tertiary care referral neurology center in Bangladesh. It is a 450-bedded Government hospital which is not designated for COVID 19 patients. However, with the increase in the number of COVID19 patients in the country a lot of patients have been found to have a positive COVID19 test during their stay in the hospital. The COVID19 test has been done in the hospitalized patients based on various symptoms of COVID19 like fever, cough, respiratory distress in addition to their neurological problem and also suspicious chest $\mathrm{x}$-ray findings and blood count. The test was done in 191 patients till 27th May 2020 of which 53(27.7\%) turned out positive. The mean age $( \pm \mathrm{SD})$ of the positive patients were $46.4( \pm 25.43)$ years (range 1 to 85 years) with $62.3 \%$ male and $37.7 \%$ female with a ratio of M:F 1.65:1. Most of the patients got admitted in the hospital with the complaints of hemiplegia $(56.6 \%)$, acute confusional state $(22.64 \%)$, altered mental status (13.20\%), weakness of all four limbs $(3.77 \%)$, weakness of both lower limbs (1.88\%), seizure $(1.88 \%)$. The neurological diagnosis was meningo-encephalitis $(65.21 \%)$, stroke $(54.71 \%)$, Guillain-Barre syndrome (5.66\%), subdural empyema $(1.88 \%)$. Five patients expired before the completion of diagnostic workup9.

It has not been possible to establish whether COVID-19 is a mere coincidence in these patients in the perspective of large-scale ongoing community transmission or it has any causal relationship with their primary diagnosis. Large scale studies are warranted to establish the fact. It has become clear from the different studies so far published, that COVID-19 has protean of neurological manifestations. Prompt recognition and early institution of therapy will minimize complications. Complications are more common in severely ill patients. Sometimes neurological symptoms may be the only presentation and many a times they can 
even precede other symptoms. Therefore, a high index of suspicion is required for prompt treatment. Large scale study from different parts of the world will lead to a better understanding of the complications which in turn would help in developing consensus regarding better treatment modalities.

[Journal of National Institute of Neurosciences Bangladesh, 2020;6(2): 72-73]

\section{References}

1. Hamming I, Timens W, Bulthuis ML, Lely AT, Navis $\mathrm{G}$, van Goor H. Tissue distribution of ACE2 protein, the functional receptor for SARS coronavirus. A first step in understanding SARS pathogenesis. J Pathol. 2004;203(2):631-7

2. Baig AM, Khaleeq A, Ali U, Syeda H. Evidence of the COVID-19 virus targeting the CNS: tissue distribution, host-virus interaction, and proposed neurotropic mechanisms. ACS Chemical Neuroscience 2020;11(7):995-8.

3. Tu H., Tu S., Gao S., Shao A., Sheng J. The epidemiological and clinical features of COVID-19 and lessons from this global infectious public health event. J Infect. 2020

4. Abdennour L, Zeghal C, Dème M, Puybasset L.
Interaction cerveau-poumon [Interaction brain-lungs]. Ann Fr Anesth Reanim. 2012;31(6):e101-7

5. Guo YR, Cao QD, Hong ZS, Tan YY, Chen SD, Jin HJ, Tan KS, Wang DY, Yan Y. The origin, transmission and clinical therapies on coronavirus disease 2019 (COVID-19) outbreak - an update on the status. Mil Med Res. 2020;7(1):11

6. Mehta P., McAuley D.F., Brown M., Sanchez E., Tattersall R.S., Manson J.J. HLH across speciality collaboration, UK. COVID-19: consider cytokine storm syndromes and immunosuppression. Lancet. 2020;395(10229):1033-1034.

7. Tveito K. Cytokine storms in COVID-19 cases? Tidsskr Nor Laegeforen. 2020;23:140

8. Khatoon F, Prasad K, Kumar V. Neurological manifestations of COVID-19: available evidences and a new paradigm. J Neurovirol. 2020;26(5):619-630

9. Hussain ME, Hoque MA, Alam MB, Yusuf MA, Chowdhury RN, Mohammad QD. Neurological Manifestations of COVID-19 patients: An Updated Review and Observations of COVID Patients in the National Institute of Neurosciences and Hospital, Dhaka, Bangladesh. J Bangladesh Coll Phys Surg 2020;38: 122-132 